\title{
Improvement in Tribological Properties of Surface Layer of an Al Alloy by Friction Stir Processing
}

\author{
Soheyl Soleymani, Amir Abdollah-zadeh*, Sima Ahmad Alidokht \\ Department of Materials Engineering, Tarbiat Modares University, Tehran, Iran. \\ Email: zadeh@modares.ac.ir
}

Received May 28 ${ }^{\text {th }}, 2011$; revised July $11^{\text {th }}$, accepted $20^{\text {th }}, 2011$.

\begin{abstract}
An innovative technique, friction stir processing (FSP) was employed to modify the surface layer of Al5083 alloy. The FSP passes of 1 to 4 were applied on alloy samples. The processed samples were subjected to microstructural analysis and dry sliding wear test. FSP resulted in microstructural refinement and improvement in wear resistance of Al5083. Moreover, the results indicated that the more number of FSP passes were found to be more effective in improvement of wear resistance, due to more microstructural refinement. It was also found that the load bearing capacity of samples significantly improved with increasing the number of FSP passes.
\end{abstract}

Keywords: Friction Stir Processing, Wear, Grain Refinement, Friction Coefficient

\section{Introduction}

Surface properties such as wear resistance can determine the service life of components in many industrial applications. Components which are produced by aluminum and its alloys, exhibit poor tribological properties leading even to seizure under detrimental conditions. Hence, There is a strong drive to develop new Al-based materials with greater resistance to wear and better tribological properties [1,2]. Recently, much attention has been paid to FSP that is known as a surface modification technique $[3,4]$. FSP which was developed based on the principle of friction stir welding (FSW), is remarkably simple. A rotating tool with a pin and shoulder is inserted into a single piece of material and results in significant microstructural changes in the processed zone, due to intense plastic deformation. FSP has been proved to be an effective way to refine the microstructure of aluminum alloys, and thereby improve the mechanical properties $[5,6]$. Previous investigations [7,8] have indicated that a fine grain structure affects the tribological properties of surface layer. Prasada et al. $[9,10]$ reported that the grain refinement leads to the improvement of wear resistance and load bearing capacity of Al-7Si alloy. Chandrashekharaiah and Kori [11] also reported similar results for different Al-based alloys. One of the major problems associated with Al5083 like other aluminum alloys, is their relatively poor wear resistance which limits their tribological performance [12].
The aim of this study is to investigate the effects of multiple FSP passes on microstrutural and tribological properties of Al5083 alloy. Besides, the effects of the applied normal force during sliding have been studied in order to find out the wear mechanisms in details.

\section{Experimental Procedure}

The base metal was commercially Al5083 rolled plates of $3 \mathrm{~mm}$ thickness with a nominal composition of $4.3 \mathrm{Mg}$ $-0.68 \mathrm{Mn}-0.15 \mathrm{Si}-$ bal. Al (in wt pct). FSP was applied on the surface of the alloy by a tool made of steel $\mathrm{H}-13$ with a shoulder of $20 \mathrm{~mm}$ diameter and a pin of $6 \mathrm{~mm}$ diagonal length and $2.8 \mathrm{~mm}$ height.

Samples were subjected to 1 to 4 FSP passes along the same direction with rotation rate of $1250 \mathrm{rpm}$ and travel speed of $50 \mathrm{~mm} / \mathrm{min}$ in room temperature.

Microstructural observations were performed on specimens by transmission electron microscopy (TEM). The hardness of the surface composite layers was measured using $31.25 \mathrm{KgF}$. Wear behavior of the specimens was evaluated by using a pin-on-disk tester at room temperature. Pin specimens with $5 \mathrm{~mm}$ diameter were cut from the processed zone of each sample and ground on emery paper up to grade 320. Counterparts were Discs made of AISI D3 steel with hardness of 58 HRc. The tests were carried out at normal loads of 1 to $5 \mathrm{KN}$ and the rotation speed of $60 \mathrm{rpm}$. The friction force was recorded automatically against sliding distance by the tester software. The wear weight loss was measured with an accuracy of 
$\pm 0.01 \mathrm{mg}$. The worn surfaces of samples were studied using scanning electron microscopy (SEM).

\section{Results and Discussions}

Figure 1 shows typical TEM microstructure of processed zone for the 1-pass and 4-pass samples. Figure 2 also shows the variations of grain size of base metal and samples processed at 1 to 4 FSP passes. The results indicated that FSP has led to the grain refinement. Moreover, increasing the number of FSP passes has resulted in decreasing grain size of processed zone. Previous investigations $[13,14]$ have indicated that in FSP/W, a continuous dynamic recrystallization phenomenon occurs due to the tool pin disruptive mechanical action and the frictional heat produced. This phenomenon can lead to intensive microstructural refinement. Increasing the number of FSP passes probably has led to occurrence of more dynamic recrystallization.

Figure 3 shows the mean hardness of base metal and processed zone of 1 to 4-pass samples. As can be seen in this figure, FSP has led to the increase in the hardness of

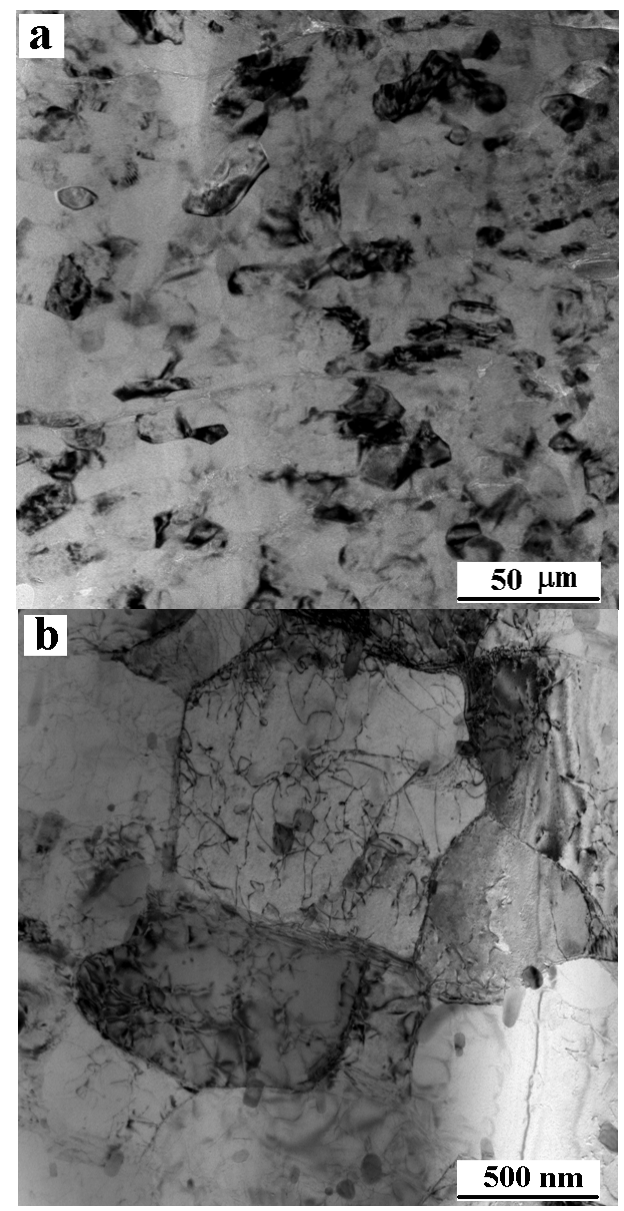

Figure 1. TEM micrographs of the surface of (a) 1-pass and (b) 4-pass samples.

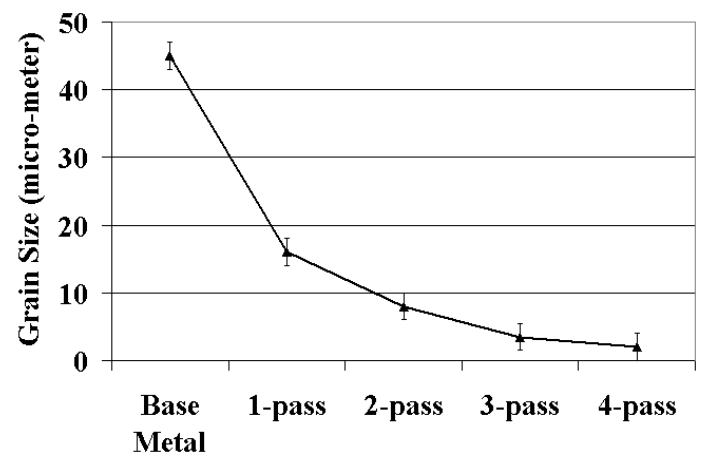

Figure 2. Variations of grain size of base metal and samples processed under 1 to 4 FSP passes.

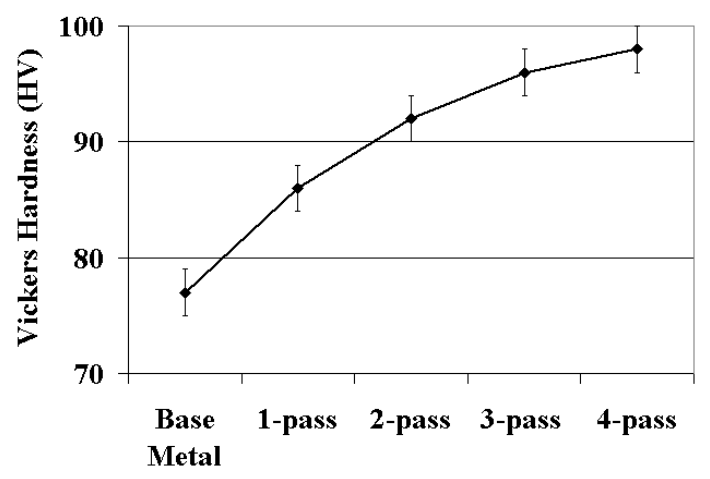

Figure 3. Variations of mean Vickers hardness (HV) of processed zone of base metal and samples produced by different number of FSP passes.

material in comparison to as-received sample. Furthermore, increasing the number of FSP passes has resulted in more increase in hardness of samples. These results are in good agreement with microstructural observations and may be attributed to the increase in yield strength of material owing to microstructural refinement in accordance with Hall-Petch relation $[5,6]$.

Figure 4 shows wear weight loss of base metal and 1 to 4-pass FSP samples. The results indicate that FSP has led to the decrease in wear weight loss compared with as-received metal and hence improving wear resistance. This can be attributed to the increase in hardness due to microstructural refinement. Besides, as can be seen in this figure, wear weight loss of samples decreases with the increase in the number of FSP passes. This observation is in good agreement with the trend observed for the hardness of the samples (Figure 3). Increasing the hardness of metal can lead to occurrence of less plastic deformation during sliding $[9,10]$. The results indicate that FSP can lead to the improvement of wear resistance as well as hardness especially for higher number of FSP passes due to the improvement of microstructural characteristics.

Figure 5 shows the variations of friction coefficient 


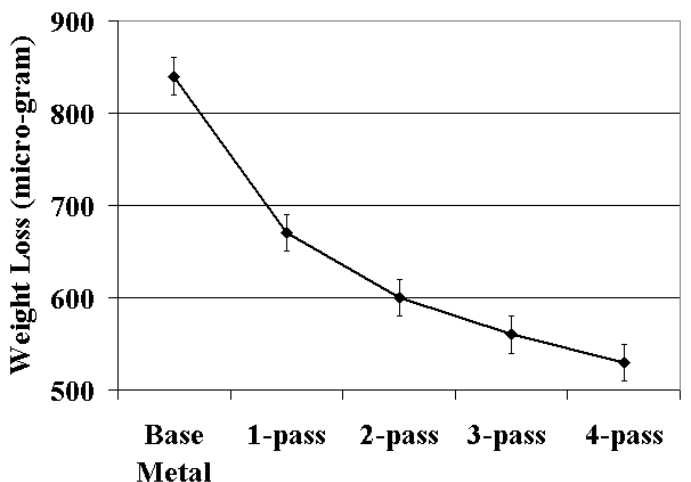

Figure 4. Variations of weight loss of base metal and samples produced by different number of FSP passes.

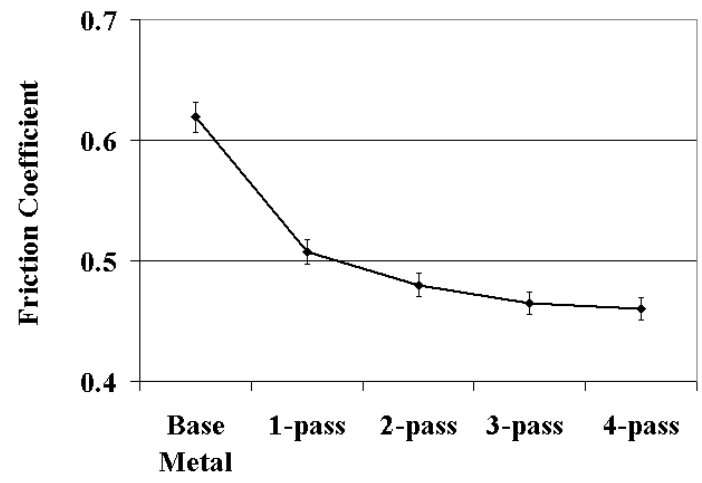

Figure 5. Variations of mean friction coefficient of processed zone of base metal and samples produced by different number of FSP passes.

for different samples. As can be seen in this figure, FSP has led to the decrease in friction coefficient of samples in comparison to base metal. Moreover, increasing the number of FSP passes has led to the decrease in the amount of mean friction coefficient. These results can be attributed to the differences in the extent of localized plastic deformation at real contact areas of samples and counterface. Harder surfaces of FSP samples have led to less plastic deformation and lower friction coefficient. It seems that higher number of passes results in decreasing plastic deformation on the surface which may be attributed to the microstructural refinement due to FSP [9].

Figure 6(a) shows the variations of weight loss of 4-pass samples worn under different applied forces. As can be seen in this figure, wear weight loss decreases with decreasing the applied force. Figure 6(b) also shows that with the decrease in the applied force, friction coefficient decreases. These observations are in good agreement with the wear laws and may be related to the decrease in contact area between counter surfaces which results in decreasing in the weight loss and friction coefficient $[15,16]$.

Figure 7 illustrates the surface of base metal. The signs

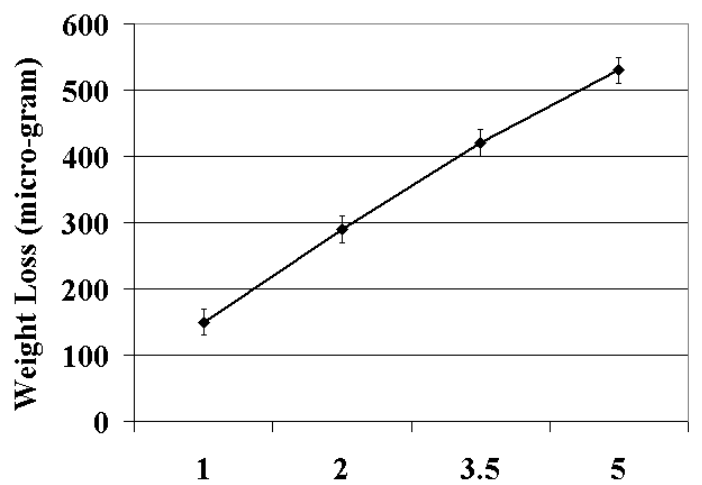

(a)

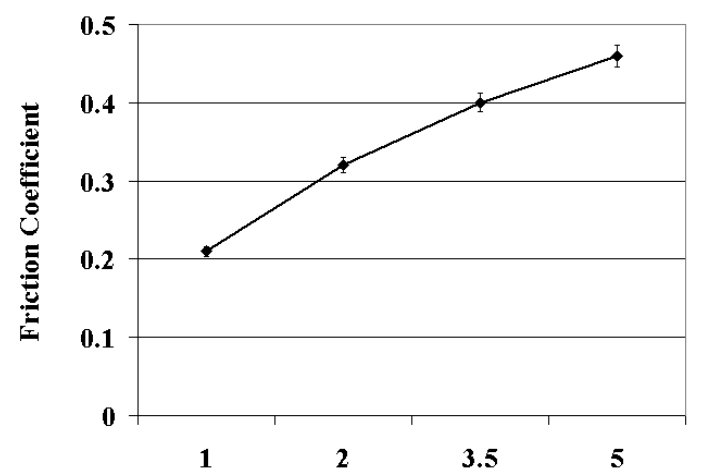

(b)

Figure 6. Variations of (a) weight loss and (b) friction coefficients of 4-pass samples worn under different applied forces (KgF).

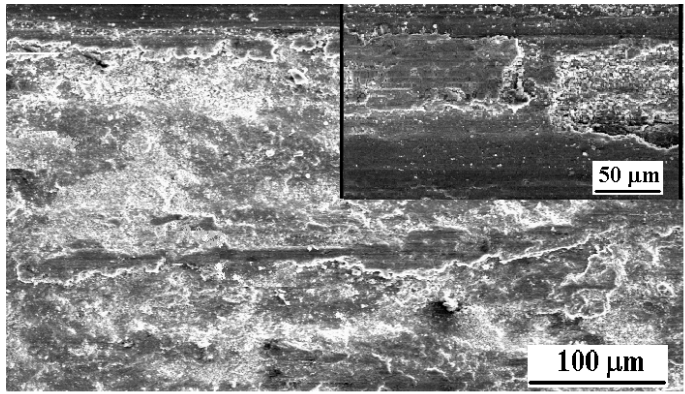

Figure 7. SEM micrograph of surface of base metal sample worn under $5 \mathrm{KN}$ applied force.

of adhesion mechanism can be seen in different parts of the surface of as-received metal sample. The lower hardness of as-received metal has led to the adhesion mechanism. The high friction coefficient of as-received sample may be due to the increase in the friction force needed to overcome the highly adhesive contact between tested surface and counterpart. The high wear weight loss of as-received sample can be the result of the adhesion mechanism operating on the surface during dry sliding. The results indicated that as-received sample has higher level of surface damages among test samples. These may 
be attributed to lower hardness and higher mean grain size of this sample.

Figure 8 shows the worn surfaces of FSP samples. As can be seen in this figure, delamination and abrasion are active wear mechanisms for the samples produced by 1 to 4 FSP passes and worn under $5 \mathrm{KN}$ applied force. When the number of FSP passes increases, the hardness of samples increases and the amount of grooves and cracks which are associated with delamination mechanism, also decrease and hence 4-pass sample shows the lowest level of surface damages (Figure 8(d)). The decrease in the signs of delamination mechanism with increasing FSP passes may be attributed to the improvement of metal resistance to cracks nucleation and growth. This may be due to the increase in toughness of material
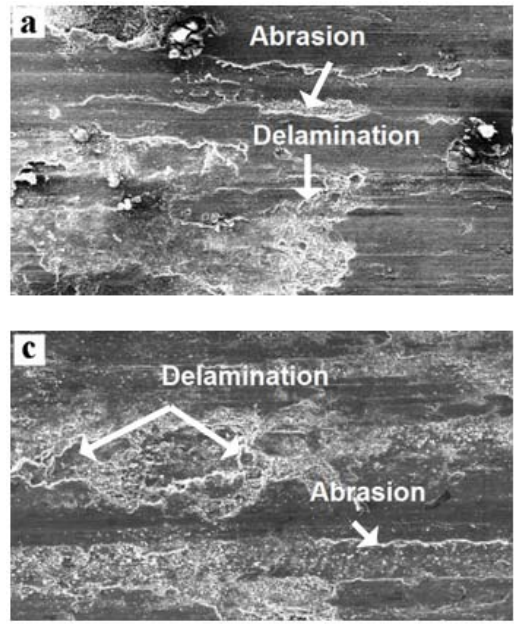

resulted by grain refinement $[7,8]$.

As mentioned earlier, friction coefficient of samples decreases with increasing the number of passes. This can lead to the decrease in the level of shear stresses applied to subsurface layers of material during sliding. This phenomenon results in decreasing the probability of nucleation and growth of subsurface cracks during sliding and leads to diminishing the signs of delamination mechanism. Therefore, the wear weight loss decreases with increasing FSP passes due to the higher resistance of material to cracks propagation.

The surfaces of 4-pass samples worn under different applied forces have been illustrated in Figure 9. Decreasing the applied force during sliding, has led to the decrease in the existence of subsurface cracks and width
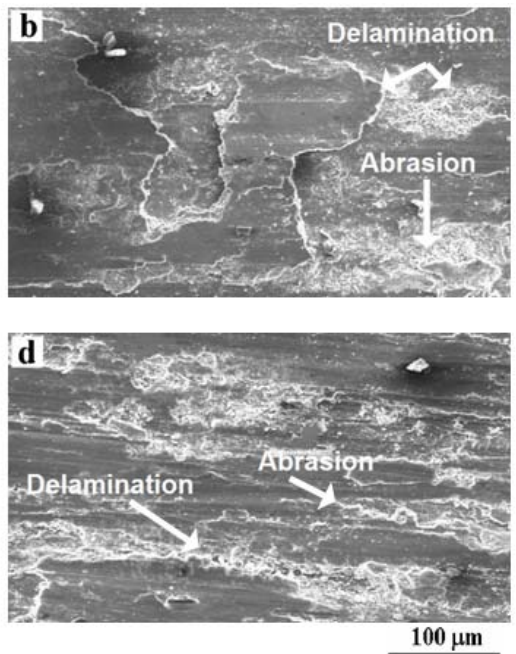

Figure 8. SEM micrographs of surfaces worn under $5 \mathrm{KN}$ applied force for the specimens made from: (a) 1-pass; (b) 2-pass; (c) 3-pass and (d) 4-pass samples.
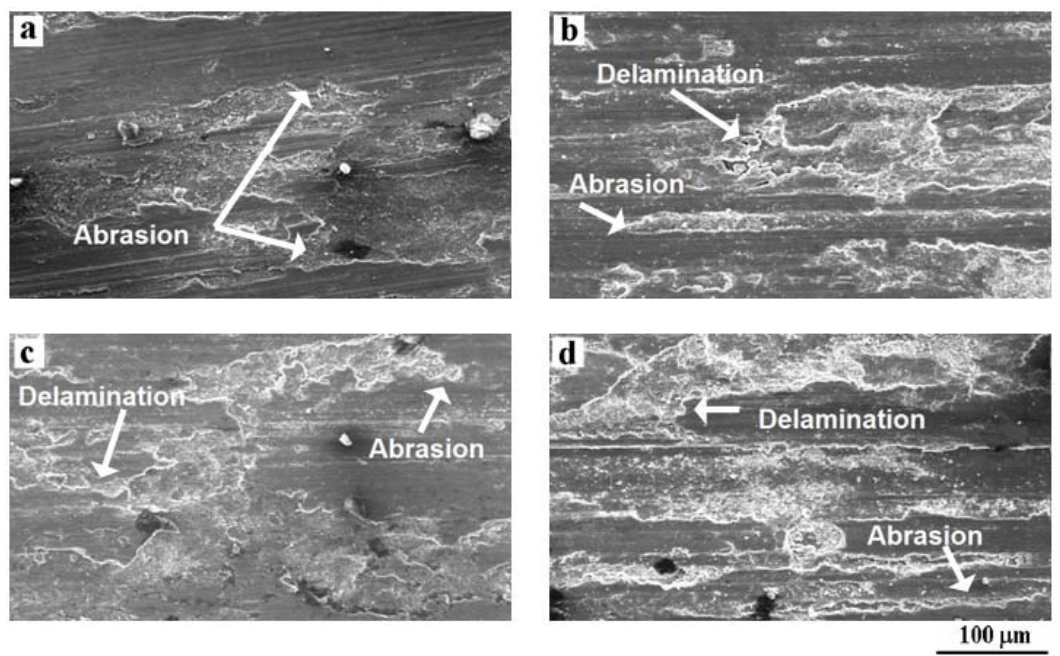

Figure 9. SEM micrographs of the surface of 4-pass samples worn under different applied forces: (a) 1 KN; (b) 2 KN; (c) 3.5 KN and (d) 5 KN samples. 
and depth of worn tracks. Besides, for the samples worn under $1 \mathrm{KN}$ applied force, the signs of delamination mechanism disappeared and abrasion was the only active wear mechanism.

As the shear stresses applied to subsurface layers of material during sliding depend directly on the normal load and friction coefficient [16], decreasing the normal load results in decreasing shear stresses and leads to the decrease in the probability of cracks propagation. Similar trends were also observed for 1 to 3-pass samples and can explain diminishing the signs of delamination mechanism with decreasing the applied force.

On the other hand, increasing the number of FSP passes leads to the decrease in friction coefficient which results in decreasing the subsurface shear stresses and signs of delamination mechanism. Therefore, observations indicate that the effects of decreasing the applied force on the worn surface of samples are similar with those related to higher FSP passes. It seems that for the samples with higher number of FSP passes, surface layer can tolerate higher applied forces during sliding. Hence, increasing the number of passes can promote wear resistance and improve the load bearing capacity of samples.

\section{Conclusions}

In the present investigation, an attempt has been made to study the effects of FSP and the number of passes on hardness and wear resistance of Al5083 alloy. The obtained results can be summarized as follows:

1) FSP resulted in grain refinement of the alloy. Moreover, increasing the number of FSP passes led to the more decrease in the size of grains. These observations could be due to the recrystallization phenomenon.

2) FSP has led to the increase in the hardness of the alloy. Increasing the number of FSP passes also led to the improvement of hardness. These can be attributed to the microstructural refinement.

3) FSP resulted in the improvement of wear resistance of the alloy. Moreover, increasing the number of FSP passes led to the improvement of wear resistance. This can be due to the increase in hardness and microstructural refinement.

4) Wear weight loss and friction coefficient decreased with decreasing the force applied during sliding. Moreover, decreasing the applied force led to diminishing surface grooves and scratches and the signs of delamination mechanism.

5) Increasing the number of FSP passes led to the decrease in weight loss and friction coefficient and also surface damages. This trend has been observed for the samples worn under lower applied forces and indicates that more FSP passes can result in the improvement of load bearing capacity of the alloy during sliding.

\section{REFERENCES}

[1] A. P. Sannino and H. J. Rack, "Dry Sliding Wear of Discontinuously Reinforced Aluminium Composites: Review and Discussion,” Wear, Vol. 189, No. 1, 1995, pp. 1-19. doi:10.1016/0043-1648(95)06657-8

[2] B. C. Pai, T. P. D. Rajan and R. M. Pillai, "Aluminium Matrix Composite Castings for Automotive Applications,” Indian Foundry Journal, Vol. 50, No. 9, 2004, pp. 30-39.

[3] S. H. Aldajah, O. O. Ajayi, G. R. Fenske and S. David, "Effect of Friction Stir Processing on the Tribological Performance of High Carbon Steel,” Wear, Vol. 267, No. 1-4, 2009, pp. 350-355. doi:10.1016/j.wear.2008.12.020

[4] M. Barmouz, P. Asadi, M. K. Besharati Givi and M. Taherishargh, "Investigation of Mechanical Properties of $\mathrm{Cu} / \mathrm{SiC}$ Composite Fabricated by FSP: Effect of SiC Particles' Size and Volume Fraction,” Materials Science and Engineering: A, Vol. 528, No. 3, 2011, pp. 1740-1749. doi:10.1016/j.msea.2010.11.006

[5] R. S. Mishra and Z. Y. Ma, "Friction Stir Welding and Processing,” Materials Science and Engineering: R: Reports, Vol. 50, No. 1-2, 2005, pp. 1-78. doi:10.1016/j.mser.2005.07.001

[6] M. L. Santella, T. Engstrom, D. Storjohann and T. Y. Pan, "Effects of Friction Stir Processing on Mechanical Properties of the cast Aluminum Alloys A319 and A356," Scripta Materialia, Vol. 53, No. 2, 2005, pp. 201-206. doi:10.1016/j.scriptamat.2005.03.040

[7] K. G. Basavakumar, P. G. Mukunda and M. Chakraborty, "Influence of Grain Refinement and Modification on Dry Sliding Wear Behaviour of Al-7Si and Al-7Si-2.5Cu Cast Alloys," Journal of Materials Processing Technology, Vol. 186, No. 1-3, 2007, pp. 236-245. doi:10.1016/j.jmatprotec.2006.12.039

[8] K. G. Basavakumar, P. G. Mukunda and M. Chakraborty, "Influence of Grain Refinement and Modification on Microstructure and Mechanical Properties of Al-7Si and Al-7Si-2.5Cu Cast Alloys,” Materials Characterization, Vol. 59, No. 3, 2008, pp. 283-289. doi:10.1016/j.matchar.2007.01.011

[9] A. K. Prasada, K. Das, B. S. Murty and M. Chakraborty, "Effect of Grain Refinement on Wear Properties of Al and Al-7Si Alloy,” Wear, Vol. 257, No. 1-2, 2004, pp. 148-153.

[10] A. K. Prasada, K. Das, B. S. Murty and M. Chakraborty, "Microstructure and the Wear Mechanism of Grain-Refined Aluminum during Dry Sliding Against Steel Disc," Wear, Vol. 264, No. 7-8, 2008, pp. 638-647. doi:10.1016/j.wear.2007.05.010

[11] T. M. Chandrashekharaiah and S.A. Kori, "Effect of Grain Refinement and Modification on the Dry Sliding Wear Behaviour of Eutectic Al-Si Alloys,” Tribology International, Vol. 42, No. 1, 2009, pp. 59-65. doi:10.1016/j.triboint.2008.05.012

[12] B. Venkataraman and G. Sundararajan, "Correlation between the Characteristics of the Mechanically Mixed Layer and Wear Behaviour of Aluminium, Al-7075 Alloy 
and Al-MMCs,” Wear, Vol. 245, No.1-2, 2000, pp. 22-38. doi:10.1016/S0043-1648(00)00463-4

[13] K. V. Jata and S. L. Semiatin, "Continuous Dynamic Recrystallization during Friction Stir Welding of High Strength Aluminum Alloys,” Scripta Materialia, Vol. 43, No. 8, 2000, pp. 743-749. doi:10.1016/S1359-6462(00)00480-2

[14] J. Q. Su, T. W. Nelson, R. Mishra and M. Mahoney, "Mi- crostructural Investigation of Friction Stir Welded 7050T654 Aluminium,” Acta Materialia, Vol. 51, No. 3, 2003, pp. 713-729. doi:10.1016/S1359-6454(02)00449-4

[15] G. W. Stachowiak, "Wear-Materials, Mechanisms and Practice,” John Wiley \& Sons Limited, England, 2005.

[16] ASM Handbook, "Friction, Lubrication, and Wear Technology," Vol. 18, ASM International, Materials Park, Ohio, 1994. 